\title{
Statistical Analysis of Cropland Area in Canada using the Autoregressive Hidden Markov Time Series Model
}

\author{
LANREWAJU O. ADEKOLA \\ Department of Physical Sciences, \\ Bells University of Technology, \\ Ota, Ogun State, \\ NIGERIA
}

\begin{abstract}
Crop production and other agricultural activities are as old as human existence and becoming increasingly intensive, spatially concentrated and specialized. However, diversification in economic activities and recent development in technology in many developed countries have led to significant increase in land use. Thereby, resulting to huge reduction in the total land area available for agricultural activities especially crop production. This study examines the distribution of cropland area in Canada in relation to three contributing factors using the Autoregressive Hidden Markov time series Model (AR-HMM) due to the limitations of the ordinary Autoregressive model in the accuracy of its parameter estimation. Expectation-Maximization (E-M) algorithm method was used to estimate the model parameters so as to investigate the effects of the factors on cropland distribution using secondary data from Food and Agriculture Organisation (FAO). Jarque-Bera and D'Agostino normality tests were carried out to examine the normality of the series. Augmented Dickey Fuller (ADF) and the KPSS tests established the stationarity of the series. The ideal stationary probability distribution for transition was at AR (3)-HMM with the minimum Bayesian Information Criterion (BIC) of 16270.62. The prior transition states for the HMM are $0.462,0.260$ and 0.278 respectively. In conclusion, this study suggests that deforestation and other land use activities as a result of commercial and technological advancements should be minimized to ensure more available cropland area.
\end{abstract}

Key-Words: - Crop production, Contributing factors, cropland area, Hidden Markov Model (HMM), Bayesian Information, Criterion (BIC)

Received: May 17, 2021. Revised: October 24, 2021. Accepted: November 3, 2021. Published: November 30, 2021.

\section{Introduction}

Agricultural development is becoming increasingly rigorous, spatially concentrated and more specialized [4]. Growth and increase in use of offfarm inputs such as machinery, chemical substances, crossbreeds and technological advancement have helped in achieving higher per hectare output and intensive capital as a substitute for labour. Farmers who are unable to employ these new technologies or whose land do not have necessary nutrient requirements usually experience low output in terms of production and income generation and may eventually go out of business as over time. [13] identifies a strong causal relationship between the use of modern agricultural inputs and crop yields and subsequently, yields and economic growth. Extensive empirical research on the causes, effects and implications of agricultural restructuring in
Canada has been examined, which includes identification of the challenges of agriculture in physically marginal areas in the 1950s and 1960s, according to [5]. As a good guide to this study, [18] also discussed Policy distortions, farm size, and the overuse of agricultural chemicals in China stating that reduction in the use of agricultural chemicals to a peak level is a critical challenge for the sustainable agricultural development. Moreover, further studies like [6] and [15] discussed extensively on urban expansion into the countryside and rural sustainability.

We should also recall that some of the carbon dioxide released into the atmosphere by fossil fuels combustion would be taken in by plant. [1] discussed extensively on the influence of agricultural land use and economic growth on nitrous oxide emissions with evidence from developed and developing countries. Hence, 
increasing deforestation and other changes in land use would lead to reduction in the carbon dioxide concentration capacity of these areas over time. Thereby resulting to huge reduction in the total area of land available for agricultural activities especially crop production. Changes in the amount of atmospheric $\mathrm{CO}_{2}$ absorption are some of the ripple effects of gaseous discharges from fossil fuel combustion, production of cement, and carbon interchange between the seas and terrestrial organisms. Variations in land use and land-cover usually influence the amount of carbon available to terrestrial environment (e.g., [9], [10], and [17]) and influence the dispersal of terrestrial carbon sources and sinks ([7] and [8]).

Greater availability of $\mathrm{CO}_{2}$ usually increases photosynthesis, which potentially hinders the growth plant. It declines the reduction that crops lose through transpiration. In general, increase in temperatures across the globe will definitely bring about increase in daily rate of evaporation and annual evaporation levels.

As marginal producers become disadvantaged and find it difficult to compete in global markets, decline in agricultural output in those areas where they are clustered is inevitable. Technological developments greatly play a major role in this process as maximum productivity income occurs in areas with level topography and moderate climate.

\section{Methodology}

\subsection{Hidden Markov Models (HMM)}

This is a class of probabilistic time series models that makes it possible for us to predict a group of unidentified (hidden) variables in a sequence of observed variables. The concepts and theories behind HMM were presented by [2] as well as [3]. HMMs have become increasingly popular in various statistical applications as a result of their usefulness and practical mathematical structure; [11] and [12].

The two major assumptions of HMM are as follows:

1. Markov Assumption: This states that the probability of generating the next state at any time $t$, is dependent on the current state only which implies that;

$$
P\left(X_{t+1} \mid X_{t}, X_{t-1}, \ldots, X_{0}\right)=p\left(X_{t+1} \mid X_{t}\right) \text { for all } t
$$

2. Independency Assumption: The likelihood of obtaining current observation symbol depends only on the current state. That is;

$$
P(Y \mid X, \lambda)=\prod_{t=1}^{T} P\left(Y_{t} \mid X_{t}, \lambda\right)
$$

in which $Y=\left\{Y_{1}, Y_{2}, \ldots, Y_{T}\right\}$ and $X=\left\{X_{1}, X_{2}, \ldots, X_{T}\right\}$ denote the observation sequence and state sequence, respectively.

Sometimes, a set of time series may comprise observations generated by different mechanisms at different intervals of time. In such situation, the observations of the series would behave in a switching to and fro manner between a set of different states. During the state to state transition, the series may experience a drastic change in means, frequencies or breadths. The Autoregressive HMM (ARHMM) are usually employed to address this type of behavior in the series.

\subsubsection{Expected-Maximization Algorithm}

(E-M)

This algorithm was initially proposed to address the issue of missing observations in the analysis of time series data set. It involves using $\alpha$, and $\beta$, the forward and backward probabilities obtained from the forward-backward algorithm and its derivation presented by [14]. The unidentified or unknown states in the HMM could be taken as missing observations in the E-M algorithm. Given a set of observation sequence $\mathrm{Y}$, the unknown state sequence $\mathrm{X}$ and the parameter set $\lambda=[\pi, A, B]$. We shall maximize equation (2) by choosing appropriate $\lambda$, according to [16]. Mathematically, the observation probability in (2) corresponds to the likelihood function of $\mathrm{Y}$ with unknown parameter $\begin{array}{lll}\text { set } & \lambda(Y \mid \lambda)=\int_{X}^{\lambda} P(Y, X \mid \lambda) & \text { as stated } \\ \text { in; } & \end{array}$

$$
=\sum_{X_{t}=1}^{N} \sum_{X_{t-1}=1}^{N} \ldots \sum_{X_{t}=1}^{N} P\left(Y, X_{1}, \ldots, X_{t} \mid \lambda\right)
$$

which gives the observation likelihood in terms of $P(Y, X \mid \lambda)$.

It would be necessary to specify another function for the expected log-likelihood, $Q\left(\lambda_{l+1} ; \lambda_{l}, Y\right)$ where the log-likelihood is denoted by $\lambda_{l+1}$ and the expectation taken wrt $\lambda_{l}$, a new parameter set :

$$
Q\left(\lambda_{l+1} ; \lambda_{t}, Y\right)=\int_{X} \log \left(P\left(Y, X \mid \lambda_{l+1}\right)\right) P\left(Y, X \mid \lambda_{l}\right)
$$

The entire procedure usually begins with an initial estimate of parameter set $\hat{\lambda}_{0}$. Next, $\hat{\lambda}_{l+1}(l=0,1, \ldots)$ would be solved iteratively until 
the function that gives the maximum value for $Q\left(\lambda_{l+1} ; \lambda_{l}, Y\right)$ is obtained as follows;

$\left.\int_{X} \frac{\partial \log P\left(Y, X \mid \lambda_{l+1}\right)}{\partial \lambda_{l+1}}\right|_{\lambda_{l+1}=\hat{\lambda}_{l+1}} \bullet Q\left(\lambda_{l+1} ; \lambda_{l}, Y\right)$

\subsubsection{E-M Formula for ARHMM}

We could recall that the Autoregressive (AR) structure of the observation vectors could be defined as:

$$
Y_{t}=S_{t}^{\prime} \beta^{\left(X_{t}\right)}+\varepsilon_{t}
$$

where;

$$
\begin{aligned}
& S_{t}=\left(1, Y_{t-1}, Y_{t-2}, \ldots, Y_{t-p}\right) \\
& \beta^{\left(X_{t}\right)}=\left(\delta^{\left(X_{t}\right)}, \beta_{1}^{\left(X_{t}\right)}, \beta_{2}^{\left(X_{t}\right)}, \ldots, \beta_{p}^{\left(X_{t}\right)}\right) \\
& \varepsilon_{t} \sim \text { i.i.d } \quad N\left(0, \sigma^{2}\right) .
\end{aligned}
$$

Hence, the conditional probability density function of $Y_{t}$ is given by:

$$
P\left(Y_{t} \mid Z_{t} ; \lambda\right)=\frac{1}{\sqrt{2 \pi} \sigma} \exp \left[\frac{-\left(Y_{t}-S_{t}^{\prime} \beta^{\left(X_{t}\right)}\right)^{2}}{2 \sigma^{2}}\right]
$$

To obtain the precise estimation formula, we differentiate (7) wrt $\beta_{j}$ and $\sigma^{-2}$

$$
\begin{gathered}
\frac{\partial \log P\left(Y_{t} \mid Z_{t} ; \theta\right)}{\partial \beta_{j}}=\left\{\begin{array}{c}
\frac{\left(Y_{t}-S_{t}^{\prime} \beta_{j}\right) S_{t}}{\sigma^{2}}, X_{t}=j \\
0, \text { otherwise }
\end{array}\right. \\
\frac{\partial \log P\left(Y_{t} \mid Z_{t} ; \theta\right)}{\partial \sigma^{-2}}=\left\{\begin{array}{c}
\frac{\sigma^{2}}{2}-\frac{\left(Y_{t}-S_{t}^{\prime} \beta_{j}\right)^{2}}{\sigma^{2}}, X_{t}=j \\
0, \text { otherwise }
\end{array}\right.
\end{gathered}
$$

Then,

$$
\begin{aligned}
& \sum_{t=p+1}^{T} \frac{\left(Y_{t}-S_{t}^{\prime} \beta_{j}^{(l+1)}\right) S_{t}}{\sigma_{(l+1)}^{2}} P\left(X_{t}=j \mid Y ; \lambda_{l}\right)=0 \\
& \sum_{t=p+1}^{T} \sum_{j=1}^{N}\left[\frac{\sigma_{(l+1)}^{2}}{2}-\frac{\left(Y_{t}-S_{t}^{\prime} \beta_{j}^{(l+1)}\right)^{2}}{2}\right] P\left(X_{t}=j \mid Y ; \lambda_{l}\right)=0
\end{aligned}
$$

The estimate of $\beta_{j}^{(l+1)}$ which gives the solution to (8) can be obtained using the Ordinary Least Square (OLS) regression of $\tilde{Y}_{t}(j)$ on $\tilde{S}_{t}(j)$ :

$$
\beta_{j}^{(l+1)}=\left[\sum_{t=p+1}^{T}\left[\widetilde{S}_{t}(j)\right]\left[\widetilde{S}_{t}(j)\right]^{\prime}\right]^{-1}\left[\sum_{t=p+1}^{T}\left[\widetilde{S}_{t}(j)\right] Y_{t}(j)\right]
$$

where;

$$
\begin{aligned}
& \tilde{Y}_{t}(j)=Y_{t} \sqrt{P\left(X_{t}=j \mid Y ; \lambda_{l}\right)} \\
& \tilde{S}_{t}(j)=S_{t} \sqrt{P\left(X_{t}=j \mid Y ; \lambda_{l}\right)}
\end{aligned}
$$

This implies that the estimation of $\sigma_{(l+1)}^{2}$ is:

$$
\sigma_{(l+1)}^{2}=\sum_{t=p+1}^{T} \sum_{j=1}^{N} \frac{\left(\tilde{Y}_{t}(j)-\tilde{S}_{t}(j) \beta_{j}^{(l+1)}\right)^{2}}{T-p}
$$

The estimate of the transition probabilities $A=\left[a_{i j}\right]$ and $\pi=\left[\pi_{j}\right]$, the initial probabilities are given by:

$$
a_{i j}^{(l+1)}=\frac{\sum_{t=p+1}^{T} P\left(X_{t}=j, X_{t-1}=j \mid Y ; \lambda_{l}\right)}{\sum_{t=p+1}^{T} P\left(X_{t-1}=j \mid Y ; \lambda_{l}\right)}
$$

and

$$
\begin{gathered}
\pi_{j}^{(l+1)}=P\left(X_{p}=j \mid Y ; \lambda_{l}\right), j=1,2, \ldots, N-1 \\
\pi_{N}^{(l+1)}=1-\pi_{1}^{(l+1)}-\pi_{2}^{(l+1)}-\ldots-\pi_{N-1}^{(l+1)}
\end{gathered},
$$

\subsubsection{The Smoothed Probabilities}

Each iteration of the re-estimation equation in the previous section would involve the calculation of the smoothed probabilities which include $P\left(X_{t}, X_{t-1} \mid Y\right)$ and $P\left(X_{t} \mid Y\right)$. When it comes to ARHMM, procedures for the iteration and calculation of the smoothed probability $P\left(X_{t}, X_{t-1}, \ldots X_{t-p} \mid Y\right)$ are as follows, where $p$ represents degree of the Autoregressive (AR) process as usual.

1. The initial stage requires the initialization of;

$$
\left.P\left(Y_{p+1} \mid Y^{(p)}\right)=\sum \sum \cdots \sum P\left(X_{p+1} \mid X_{p}\right) \cdot P\left(Y_{p+1} \mid\right) Z_{p+1}\right) \pi_{X_{p}, \ldots . X_{1}}
$$

and

$$
\begin{aligned}
& P\left(X_{p+1}, \ldots, X_{1} \mid Y^{(p+1)}\right) \\
& =\frac{P\left(X_{p+1} \mid X_{p}\right) P\left(Y p+1 \mid Z_{p+1}\right) \pi_{X_{p}, \ldots, X 1}}{P\left(Y p+1 \mid Y^{(p)}\right)}
\end{aligned}
$$

where: $Y^{(t)}=\left(Y_{1}, Y_{2}, \ldots, Y_{t}\right)^{\prime}$

$$
\begin{aligned}
& Z_{t}=\left\{X_{t}, X_{t-1}, . ., X_{t-p}, Y_{t-1}, Y_{t-2}, \ldots, Y_{t=p}\right\}^{\prime} \\
& \pi_{X_{p}, X_{p-1}, \ldots, X_{1}}=P\left(X_{p}, X_{p-1}, \ldots, X_{1} \mid Y\right)
\end{aligned}
$$

2. Estimate $\quad P\left(Y_{t} \mid Y^{(t-1)}\right) \quad$ and $P\left(X_{t}, X_{t-1}, \ldots, X_{t-p} \mid Y^{(t)}\right)$ for $t=p+2, \ldots, T$ using; 


$$
\begin{aligned}
& P\left(Y_{t} \mid Y^{(t-1)}\right) \\
& =\sum_{X_{t=1}}^{N} \sum_{X_{t-1=1}}^{N} \sum_{X_{t-p-1=1}}^{N} P\left(X_{t} \mid X_{t-1}\right) P\left(Y_{t} \mid Z_{t}\right) P\left(X_{t-1}, \ldots, X_{t-p-1 \mid} Y^{(t-1)}\right) \\
& P\left(X_{t}, \ldots, X_{t-p} \mid Y^{(t)}\right) \\
& =\frac{\sum_{X_{t-p-1=1}}^{N} P\left(X_{t} \mid X_{t-1}\right) P\left(Y_{t} \mid Z_{t}\right) P\left(X_{t-1}, \ldots, X_{t-p-1} \mid Y^{(t-1)}\right)}{P\left(Y_{t} \mid Y^{(t-1)}\right)}
\end{aligned}
$$

3. Calculate the advanced probability for $\tau=t+1, t+2, \ldots, t+p ;$ for a given $t$, as follows;

$$
P\left(X_{\tau}, \ldots, X_{t-p} \mid Y^{(\tau)}\right)=\frac{P\left(X_{\tau} \mid X_{\tau-1}\right) P\left(Y_{\tau} \mid Z_{\tau}\right) P\left(X_{\tau-1}, \ldots, X_{t-p} \mid Y^{(\tau-1)}\right)}{P\left(Y_{\tau} \mid Y^{(\tau-1)}\right)}
$$

4. The inference for $\tau=t+p+1, t+p+2, \ldots, P$ brought forward as;

$$
\begin{aligned}
& P\left(X_{\tau}, \ldots, X_{\tau-p}, X_{t}, \ldots, X_{t-p} \mid Y^{(\tau)}\right) \\
& =\frac{\sum_{X_{\tau-p-1=1}}^{N} P\left(X_{\tau} \mid X_{\tau-1}\right) P\left(Y_{\tau} \mid Z_{\tau}\right) P\left(X_{\tau-1}, \ldots, X_{\tau-p-1}, X_{t}, \ldots, X_{t-p} \mid Y^{(\tau-1)}\right)}{P\left(Y_{\tau} \mid Y^{(\tau-1)}\right)}
\end{aligned}
$$

5. Finally, we would sum up the last $p$ states;

$$
\begin{aligned}
& P\left(X_{t}, X_{t-1}, \ldots, X_{t-p} \mid Y\right) \\
& =\sum_{X_{T=1}}^{N} \sum_{X_{T-1=1}}^{N} \ldots \sum_{X_{T-p=1}}^{N} P\left(X_{T}, \ldots, X_{T-p}, X_{t}, \ldots, X_{t-p} \mid Y^{(T)}\right)
\end{aligned}
$$

In general, the total number of steps expected to go through during the algorithm is of order $N^{2(p+1)} T^{2}$ due to the fact that $N$ and $p$ are usually fairly small.

\section{Results and Discussion}

\subsection{The Time plot for the factors}

\subsection{Descriptive Statistics and analysis}
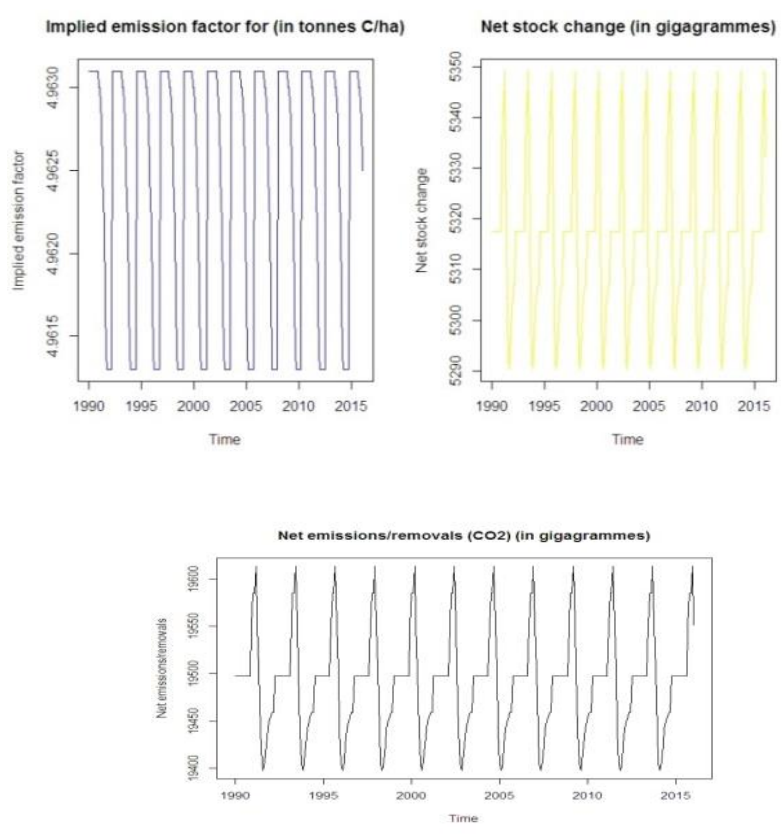

Fig.1: The Time plots for Implied emission factor for (in tonnes $\mathrm{C} / \mathrm{ha}$ ) and Net stock change (in gigagrammes) and Net emissions/removal $\left(\mathrm{CO}_{2}\right)$ (in gigagrames) respectively.

From the time plots in fig.1, the implied emission factor measured (in tonnes $\mathrm{C} / \mathrm{ha}$ ) started with the highest level of 4.9631in 1990 in contributing to the Area (ha) of land. However, from 1990 to around 1992, there was a drastic continual drop of implied emission factor to a limit point of 4.9615 , before a continual increment in contributing to emission factor back to an apex point of 4.9631. It continued in zigzag bounded phenomena of $(4.9631,4.9615)$ until it reaches 2016. In a similar manner, the net stock change (in gigagrammes) started with an upper limit bound of 5350 in gigagrammes between 1991 and 1992 and gradually geared down its quality to reach a value of 5290. Similarly to implied emission factor, the net stock changed in a zigzag manner and bounded by via $(5350,5290)$, but with a based factor around 5315 .

In a similar vein, the net emission $\left(\mathrm{CO}_{2}\right)$ measured in gigagrammes started its contribution to the area of land via an upper limit bound of 16900 in gigagrammes between 1991 and 1992, and gradually geared down its quality to reach point 16400. Similarly to the net stock change, the net emission $\left(\mathrm{CO}_{2}\right)$ in a zigzag manner and bounded by via $(16900,16400)$, but with a based factor around 16480 . 
Table 1. Stationary Tests, Skewed Coefficient of Implied emission factor for implied emission (in tonnes C/ha)

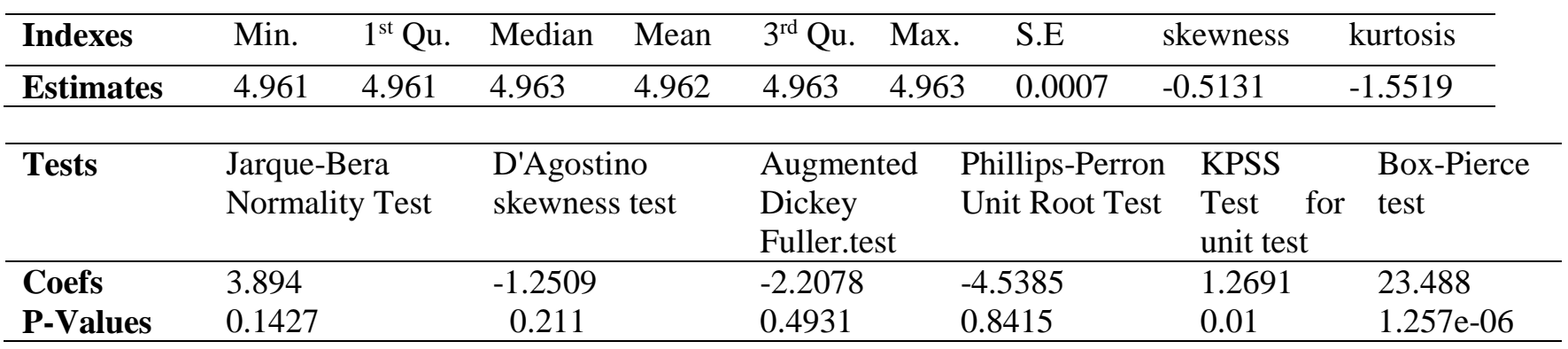

The minimum and maximum emitted factor in tonnes $(\mathrm{C} / \mathrm{ha})$ that contributed to the Canadian area of land mass were 4.961 and 4.963 respectively over the twenty-seven (27) years. However, the range is 0.002 , while the emitted factor for improving the area of hectares was clustered around 4.962. The variation among the emitted factors in contribution to the area was estimated to be $0.0007(0.07 \%)$, which suggested a lesser (in fact a negligible Coefficient of Variation) dispersed variation among the factors. The value of the median conjoined with the value of the mean approximately, which indicated a normally formed whisker in the QQ-plot, but might be of leptokurtic or platykurtic. In addition, since the kurtosis, -1.5519 is less than 3 , the distribution of the emitted factors has a lighter tails (less in the tails) than the Gaussian. The skewness is -0.5131 . In this case, the Left Hand (LH) tail is usually longer than the Right Hand (RH) tail, but if skewness lies between -1 and -0.5 or 0.5 and 1, the series is said to be moderately skewed. The Augmented Dickey Fuller (ADF) test value is 2.2078 and the corresponding one-sided P-value is 0.4931 , it is to be noted that the level of significance (critical values) is greater than the P-value. So, there is no sufficient proof to reject the Null hypothesis of trend stationarity. The KPSS Test for level of unit root test statistic value is -1.2691 and the associated one-sided P-value $=0.01$, revealed that there is constancy in the variance in the long run (homoscedasticity via residual error), that is, no problem of heteroscedasticity. While the PhillipsPerron unit root test questioned the accuracy of to be estimated or modified parameters via Autoregressive alone because P-value $=0.8415$ is greater than $5 \%$ level of significant.

Table 2. Stationary Tests, Skewed Coefficient of Net stock change (in gigagrammes)

\begin{tabular}{lccccccccc}
\hline Indexes & Min. & $\begin{array}{l}1^{\text {st }} \\
\text { Qu. }\end{array}$ & Median & Mean & $\begin{array}{l}3^{\text {rd }} \\
\text { Qu. }\end{array}$ & Max. & S.E & Skewness & kurtosis \\
\hline Estimates & 5290 & 5306 & 5318 & 5316 & 5318 & 5349 & 14.6553 & 0.3627 & -0.1904 \\
\hline
\end{tabular}

\begin{tabular}{llllllrl}
\hline Tests & Jarque-Bera & D'Agostino & Augmented & Phillips- & KPSS & Test & Box- \\
& Normality & skewness & Dickey & Perron Unit for Level & Pierce test \\
& Test & test & Fuller.test & Root Test & Stationarity & \\
\hline
\end{tabular}




\begin{tabular}{lllllll}
\hline Coefs & 3.3846 & 2.6031 & -7.3542 & -67.546 & 0.0199 & 242.31 \\
P-Values & 0.2819 & 0.0092 & 0.01 & 0.01 & 0.1 & $<2.2 \mathrm{e}-16$ \\
\hline
\end{tabular}

From table 2 showing the summary for net stock change, the minimum and maximum net stock change (in gigagrammes) that contributed to the Canadian area of land mass were 5290 and 5349 respectively over the twenty-seven (27) years. However, the range is 59, while the net stock changes for improving the area of hectares was clustered around 5316. The variation among the net stock changes in contribution to the area was estimated to be $14.6553(0.146 \%)$, which still suggested a moderately dispersed variation among the factors. Contrarily, the value of the median (5318) was non-conjoined with the value of the mean (5316), but the median (5318) coincide with the maximum value of the net stock changes. This indicated a slight deviation from the normally formed whisker in the QQ-plot, but might be of leptokurtic or platykurtic. In addition, since the kurtosis, -0.1904 is less than 3 ; the distribution of the net stock changes has a lighter tails (less in the tails) than the Gaussian. The skewness is 0.3627. In this situation, the LH tail is longer than the RH tail, but the rule of thumb says if skewness lies between 1 and -0.5 or between 0.5 and 1 , then there exists moderately skewed set of data. The ADF statistic value is -7.3542 and the corresponding one-sided $\mathrm{P}$ value is 0.01 , it is to be noted that the critical value is greater than the P-value. Hence, no satisfactory evidence for the rejection of the Null hypothesis of trend stationarity. The KPSS Test for level of unit root test statistic value is 0.0199 and the associated one-sided $\mathrm{P}$-value $=0.1$, concluded that there is constancy in the variance in the long run (homoscedasticity via residual error), that is, no problem of heteroscedasticity. While the PhillipsPerron unit root test put hold, the question of the accuracy of to be estimated or modified parameters via Autoregressive alone because $\mathrm{P}$-value $=0.01$ is less than $5 \%$ level of significance.

Table 3. Stationary Tests, Skewed Coefficient of Net emissions/removals $\left(\mathrm{CO}_{2}\right)$ (in gigagrammes)

\begin{tabular}{llllllllll}
\hline Indexes & Min. & $1^{\text {st }} \mathrm{Qu}$. & Median & Mean & $\begin{array}{l}3^{\text {rd }} \\
\text { Qu. }\end{array}$ & Max. & S.E & skewness & Kurtosis \\
\hline Estimate & 19400 & 19450 & 19500 & 19490 & 19500 & 19610 & 54.8168 & 0.3892 & -0.1916 \\
\hline
\end{tabular}

\begin{tabular}{llllllc}
\hline Tests & $\begin{array}{l}\text { Jarque- } \\
\text { Bera } \\
\text { Normality } \\
\text { Test }\end{array}$ & $\begin{array}{l}\text { D'Agostino } \\
\text { skewness } \\
\text { test }\end{array}$ & $\begin{array}{l}\text { Augmented } \\
\text { Dickey } \\
\text { Fuller.test }\end{array}$ & $\begin{array}{l}\text { Phillips- } \\
\text { Perron Unit } \\
\text { Root Test }\end{array}$ & $\begin{array}{l}\text { KPSS Test for } \\
\text { Level } \\
\text { Stationarity }\end{array}$ & $\begin{array}{l}\text { Box-Pierce } \\
\text { test }\end{array}$ \\
& & & & & \\
\hline Coefs & 0.7230 & 0.96093 & -3.3338 & -6.7733 & 0.4352 & 21.128 \\
P-Values & 0.6966 & 0.3366 & 0.0866 & 0.6923 & 0.0619 & $4.296 \mathrm{e}-06$ \\
\hline
\end{tabular}


From table 3, the minimum and maximum net emissions/removals $\left(\mathrm{CO}_{2}\right)$ in gigagrammes that contributed to the Canadian area of land mass were 19400 and 19610 respectively over the twenty-seven (27) years. However, the range is 210 , while the net emissions/removals $\left(\mathrm{CO}_{2}\right)$ for improving the area of hectares was clustered around 4.962. The variation among the net emissions/removals $\left(\mathrm{CO}_{2}\right)$ in contribution to the area was estimated to be $54.8168(0.548 \%)$, which suggested an alarming (above average) dispersed variation among the removals.

Contrarily, the value of the median (19500) was non-conjoined with the value of the mean (19490), which indicated a non- normally formed whisker in the QQ-plot, but might be of leptokurtic or platykurtic. In addition, since the kurtosis, 0.1916 is less than 3 , the distribution of the emitted factors has a lighter tails (less in the tails) than the Gaussian. The skewness is 0.3892. In this case, the $\mathrm{LH}$ tail is also longer than the $\mathrm{RH}$, but according to the rule of thumb, if the skewness ranges between -1 and -0.5 or between 0.5 and 1 , this implies the existence of moderately skewed data. The ADF statistic value is -3.3338 and the corresponding onesided P-value is 0.0866 . It should be noted that the critical value is greater than the P-value. Hence, we do not have substantial evidence to justify the acceptance of the Null hypothesis of trend stationarity. The KPSS Test for level of unit root test statistic value is 0.4352 and the associated onesided P-value $=0.0619$, concluded that there is no constancy in the variance in the long run (homoscedasticity via residual error), that is, constancy of variance assumption has been violated. While the Phillips-Perron unit root test questioned the accuracy of to be estimated or modified parameters via Autoregressive alone because Pvalue $=0.6923$ is greater than $5 \%$ level of significant.
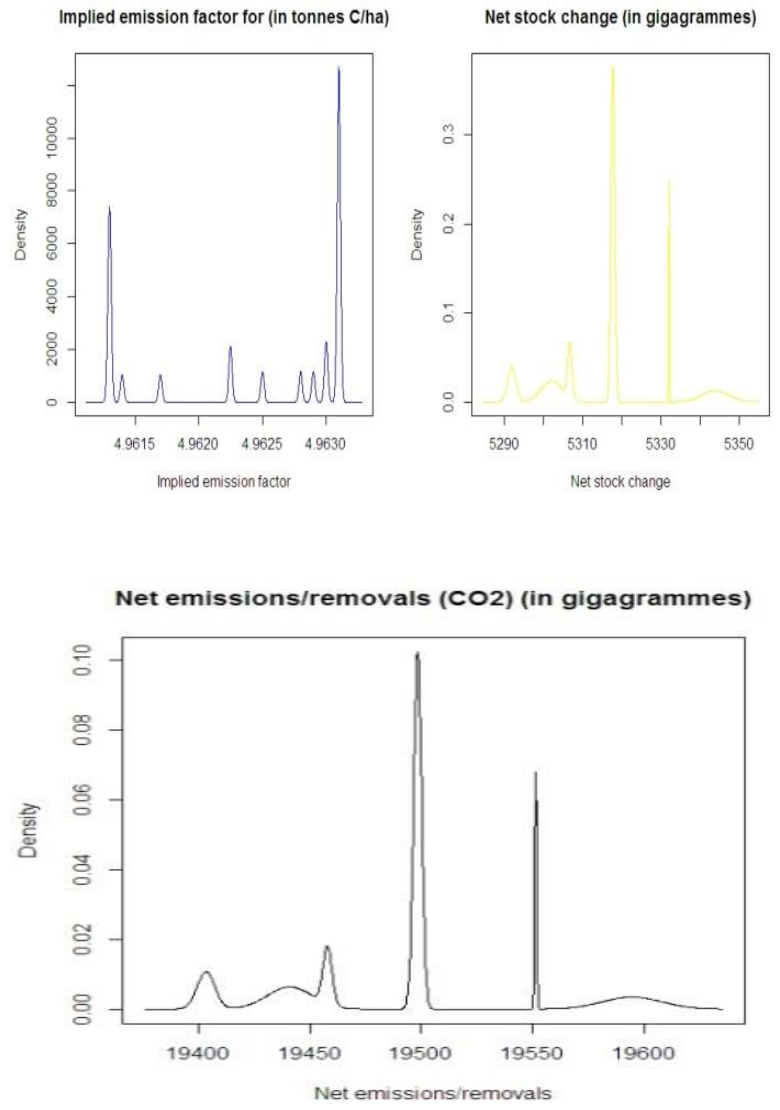

Fig. 2: The Cluster Density for Implied emission factor for (in tonnes $\mathrm{C} / \mathrm{ha}$ ) Net stock change (in gigagrammes) and Net emissions/removal $\left(\mathrm{CO}_{2}\right)$ (in Gigagrames).

From Fig.2, the density normal plots for implied emission factor for (in tonnes $\mathrm{C} / \mathrm{ha}$ ) and Net stock change (in gigagrammes) are not just single density but densities are embedded has switching. Nine (9) and four (4) switchings were recorded for implied emission factor and net stock change respectively and four (4) switchings for net emissions/removal $\left(\mathrm{CO}_{2}\right)$. This disparity in the number of switchings reveals that the series of the three agents of area changes changed not only cyclically but also via time varying. So, ordinary Autoregressive models would not be suitable enough to obtain the true estimates of the parameters. Therefore, an ARHMM Model would be used to generalize the changes of these factors. 


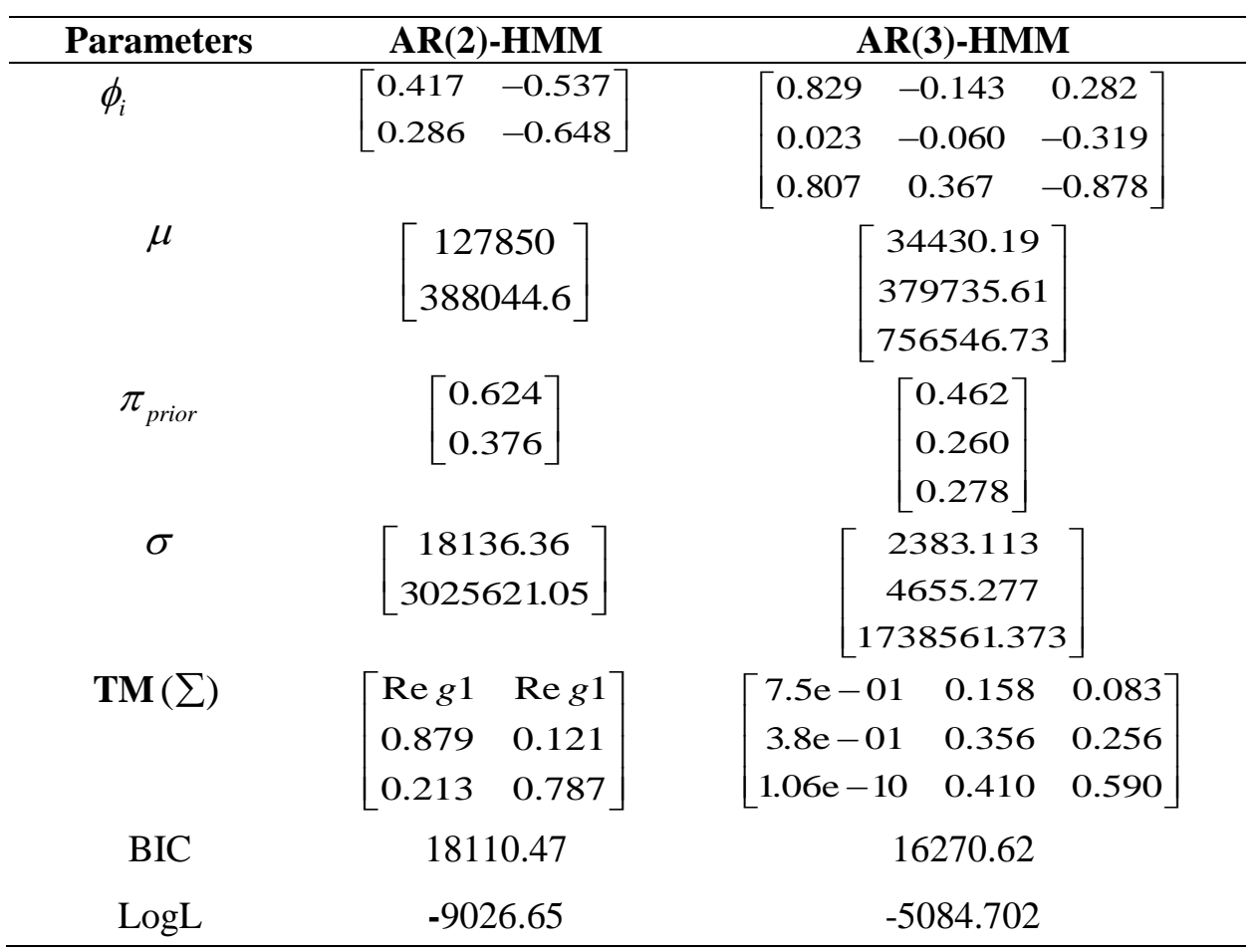

\begin{tabular}{|c|c|c|c|c|c|}
\hline \multirow{2}{*}{$\begin{array}{c}\text { Parameters } \\
\phi_{i}\end{array}$} & \multicolumn{2}{|c|}{ AR(4)-HMM } & \multicolumn{3}{|c|}{ AR(5)-HMM } \\
\hline & $0.829-0.143$ & 0.282 & 0.829 & 0.143 & $0.282^{-}$ \\
\hline & $0.023-0.060$ & -0.319 & $0.023-1$ & 0.060 & -0.319 \\
\hline & $0.807 \quad 0.367$ & -0.878 & 0.807 & .367 & -0.878 \\
\hline$\mu$ & \multicolumn{2}{|l|}{$[34430.19$} & \multicolumn{3}{|c|}{-34430197} \\
\hline & \multicolumn{2}{|l|}{379735.61} & \multicolumn{3}{|c|}{379735.61} \\
\hline & \multicolumn{2}{|l|}{756546.73} & \multicolumn{3}{|c|}{756546.73} \\
\hline \multirow{3}{*}{$\pi_{\text {prior }}$} & \multicolumn{2}{|l|}{$[0.462\rceil$} & \multicolumn{3}{|c|}{$\lceil 0.462\rceil$} \\
\hline & \multicolumn{2}{|l|}{0.260} & \multicolumn{3}{|c|}{0.260} \\
\hline & \multicolumn{2}{|l|}{0.278} & \multicolumn{3}{|c|}{0.278} \\
\hline \multirow[t]{3}{*}{$\sigma$} & \multicolumn{2}{|l|}{2383.113} & \multicolumn{3}{|c|}{2383.113} \\
\hline & \multicolumn{2}{|l|}{4655.277} & \multicolumn{3}{|c|}{4655.277} \\
\hline & \multicolumn{2}{|l|}{1738561.373} & \multicolumn{3}{|c|}{1738561.373} \\
\hline \multirow[t]{3}{*}{$\mathbf{T M}\left(\sum\right)$} & $7.5 e-01 \quad 0.158$ & 0.0837 & $7.5 e-01$ & 0.158 & $0.083]$ \\
\hline & $3.8 e-01 \quad 0.356$ & 0.256 & $3.8 \mathrm{e}-01$ & 0.356 & 0.256 \\
\hline & $1.06 \mathrm{e}-10 \quad 0.410$ & 0.590 & $1.06 \mathrm{e}-10$ & 0.410 & $0.590]$ \\
\hline $\mathrm{BIC}$ & \multicolumn{2}{|l|}{16276.62} & \multicolumn{3}{|c|}{16276.62} \\
\hline $\log L$ & \multicolumn{2}{|l|}{-6260.39} & \multicolumn{3}{|c|}{-6260.39} \\
\hline
\end{tabular}

The ideal stationary probability distribution (loglikelihood) for transition is at AR(3)-HMM. Similarly, its BIC with the smallest value also confirms it. The stationary probability distribution (log-likelihood) always goes for the model with the highest log-likelihood value. Obviously, the loglikelihood (-5084.702) for AR(3)-HMM has the highest stationary probability distribution when compared with the pool (-9026.65, -6260.39, 6260.39) for AR(2)-HMM, AR(4)-HMM and $\mathrm{AR}(5)-\mathrm{HMM}$ respectively. It is to be noted that there was even state (limiting distribution) for the area using the three factors. This implies that at AR (4)-HMM and AR (5)-HMM, regimes switching and coefficients of AR models continue to be the same and lag of AR would not exceed lag (3) despite 
indication of higher lag. The values in the stationary probability distribution vector are equivalent to the frequencies of occurrence of the recorded three states using AR (3)-HMM in the long run. The three elements prior transition state for the HMM are $0.462,0.260$ and 0.278 respectively. Hence by HMM prediction, there would be a change of state from one state to another for $46.2 \%$ of the time and the entire time of being in the abnormal state $(0.260)$ and being in the normal state $(0.278)$ would be approximately same in the long-run. In addition, the variations of contributing factors to cropland area are heavily dispersed with values 2383.113, 2774655 and 1738561.373 respectively. It was also noted that the coefficients of AR (3) for the AR (3)HMM are stationary (that is, less than one).

$$
\begin{aligned}
Y_{t}= & 34430.19^{X_{1}}+379735.61^{X_{2}}+756546.73^{X_{3}} \\
+ & 0.829 X_{t-1}-0.060 X_{t-2}-0.878 X_{t-3} \\
& \approx\left[\begin{array}{ccc}
7.5 \mathrm{e}-01 & 0.158 & 0.083 \\
3.8 \mathrm{e}-01 & 0.356 & 0.256 \\
1.06 \mathrm{e}-10 & 0.410 & 0.590
\end{array}\right]
\end{aligned}
$$

The realization transition is as given below:

$\begin{array}{lllllllllllllllllllll}1 & 1 & 1 & 1 & 1 & 1 & 1 & 1 & 1 & 1 & 1 & 2 & 2 & 2 & 2 & 2 & 2 & 2 & 1 & 1 & 1\end{array}$ $\begin{array}{llllllllll}1 & 1 & 1 & 1 & 1 & 1 & 2 & 2 & 1 & 1\end{array}$

\section{Conclusion}

In this study, we have examined the distribution of cropland area for 27 years in Canada using secondary data from Food and Agriculture organization (FAO). This distribution in relation to three contributing factors which changed cyclically with time is not normally distributed but moderately skewed and suggests the use of the Autoregressive Hidden Markov time series Model (AR-HMM). The three factors have limiting effect on the distribution and their transition has limit point on the land area and this study would suggest that deforestation, due to commercial and technological activities should be minimized to ensure more available cropland area. More so, AR-HMM time series model performed excellently in investigating the cropland area distribution.

\section{References:}

[1] Azad H., Arooj B., and Muhammad I. H. (2020). Impact of agricultural land use and economic growth on nitrous oxide emissions: Evidence from developed and developing countries. Elsevier, Science of The Total
Environment, Volume 741, 1, 140421. https://doi.org/10.1016/j.scitotenv.2020.140421.

[2] Baum, L.E. and Petrie, T. (1966). "Statistical inference for probabilistic functions of finite state Markov chains," Ann. Math. Statist., 37, 1554-1563.

[3] Baum, L.E., Petrie, T., Soules, G., and Weiss, N. (1970). "A maximization technique occurring in the statistical analysis of probabilistic functions of Markov chains," Ann. Math. Statist., 41, 164-171.

[4] Bowler I. 2002. Geography Vol. 87, No. 3, pp. 205-212 .

[5] Buckley H. and Tihanyi E. (1967). Canadian Policies for Rural Adjustment A Study of the Economic Impact for ARDA PFRA and MMRA Economic Council of Canada Special Study No 7 Ottawa.

[6] Caldwell, J. C., Bruce K. C., Pat C., Peter F M., and Thomas S. (2006). Demographic Transition Theory. Dordrecht, The Netherlands: Springer.

[7] Canadell, J. (2002), Land use effects on terrestrial carbon sources and sinks, Sci. China, Ser. C, Life Sci., 45, suppl., 1-9.

[8] Dargaville, R. J., Heimann, M., McGuire, A. D., Prentice, I. C., Kicklighter, D. W., Joos, F., Clein, J. S., Esser, G., Foley. J., Kaplan, J., Meier, R. A., Melillo, J. M., Moore III, B., Ramankutty, N., Reichenau, T., Schloss, A., Sitch, S., Tian, H., Williams L. J. and Wittenberg U. (2002), Evaluation of terrestrial carbon cycle models with atmospheric $\quad \mathrm{CO}_{2}$ measurements: Results from transient simulations considering increasing $\mathrm{CO}_{2}$, climate, and land-use effects, Global Biogeochem. Cycles, 16 (4), 1092, doi:10.1029/2001GB001426.

[9] Foley, J. A., DeFries R., Asner G. P., Carol B., Bonan, G. and Stephen R. C. (2005). Global consequences of land use, Science, $309 \quad$ (5734), 570-574.

[10] Houghton, R. A. (1999), The annual net flux of carbon to the atmosphere from changes in land use 1850-1990, Tellus, Ser. B, Chem. Phys. Meteorol., 51 (2), 298- 313.

[11] James D. H. and Baldev Raj (Editors). (2002). Advances in Markov- Switching Models. Heidelberg, New York. PhysicaVerl.

[12] MacDonald, I. L. and Zucchini, W. (1997). Hidden Markov and Other Models for 
Discrete-valued Time Series. Chapman \& Hall.

[13] McArthur, J.W., \& McCord, G.C. (2014). "Fertilizing growth: Agricultural inputs and their effects in economic development." Global Economy and Development Working Paper No. 77. Brookings Institute: Washington, DC

[14] Murphy K. P. (2012). Machine Learning: A Probabilistic Perspective, Cambridge, MA: MIT Pres.

[15] Pierce J. T. (1983). Resource and economic considerations in the allocation of agricultural land in peri-urban areas: A Canadian perspective Landscape Planning, Elsevier. Vol. 10, Issue 4, Pages 363-386.

[16] Qian, W. and Titterington, D. M. (1991). Estimation of parameters in Hidden

Makov Models. Phil. Trans. R. Soc. Lond. A 337, p.p. 407- 428.

[17] Smith, T. M., W. P. Cramer, R. K. Dixon, R. Leemans, R. P. Neilson, and Solomon A. M. (1993), The global terrestrial carbon cycle, Water Air Soil Pollute., 70(1-4), 19-37.

[18] Yiyun Wu, Xican Xi, Xin Tang, Deming Luo, Baojing Gu, Shu Kee Lam, Peter M. Vitousek, and Deli Chen (2018). Proceedings of the National Academy of Sciences (PNAS) 115 (27) 7010-7015

https://doi.org/10.1073/pnas.180664511

5.

\section{Contribution of Individual Authors to the Creation of a Scientific Article (Ghostwriting Policy)}

Lanrewaju O. Adekola was responsible for the research work and the preparation of the manuscript

\section{Sources of Funding for Research Presented in a Scientific Article or Scientific Article Itself}

This research did not receive any specific grant from any funding agencies, whether in the private, public, commercial, or not-for-profit sectors.

\section{Creative Commons Attribution License 4.0} (Attribution 4.0 International, CC BY 4.0)

This article is published under the terms of the Creative Commons Attribution License 4.0 https://creativecommons.org/licenses/by/4.0/deed.en US 